\title{
Proposal of a quantitative PCR-based protocol for an optimal Pseudomonas aeruginosa detection in patients with cystic fibrosis
}

Florence Le Gall ${ }^{1,2}$, Rozenn Le Berre ${ }^{1,3}$, Sylvain Rosec ${ }^{4}$, Jeanne Hardy ${ }^{1}$, Stéphanie Gouriou ${ }^{1}$, Sylvie Boisramé-Gastrin ${ }^{1}$, Sophie Vallet ${ }^{1,2}$, Gilles Rault ${ }^{5}$, Christopher Payan ${ }^{1,2}$ and Geneviève Héry-Arnaud ${ }^{1,2^{*}}$

\begin{abstract}
Background: The lung of patients with cystic fibrosis (CF) is particularly sensitive to Pseudomonas aeruginosa. This bacterium plays an important role in the poor outcome of CF patients. During the disease progress, first acquisition of $P$. aeruginosa is the key-step in the management of CF patients. Quantitative PCR (qPCR) offers an opportunity to detect earlier the first acquisition of $P$. aeruginosa by CF patients. Given the lack of a validated protocol, our goal was to find an optimal molecular protocol for detection of $P$. aeruginosa in CF patients.

Methods: We compared two formerly described qPCR formats in early detection of $P$. aeruginosa in CF sputum samples: a qPCR targeting oprL gene, and a multiplex PCR targeting gyrB and ecfX genes.

Results: Tested in vitro on a large panel of $P$. aeruginosa isolates and others gram-negative bacilli, oprL qPCR exhibited a better sensitivity (threshold of $10 \mathrm{CFU} / \mathrm{mL}$ versus $730 \mathrm{CFU} / \mathrm{mL}$ ), whereas the gyrB/ecfX qPCR exhibited a better specificity ( $90 \%$ versus $73 \%$ ). These results were validated ex vivo on 46 CF sputum samples positive for P. aeruginosa in culture. Ex vivo assays revealed that QPCR detected 100 times more bacterial cells than culturebased method did.

Conclusion: Based on these results, we proposed a reference molecular protocol combining the two qPCRs, which offers a sensitivity of $100 \%$ with a threshold of $10 \mathrm{CFU} / \mathrm{mL}$ and a specificity of $100 \%$. This combined qPCR-based protocol can be adapted and used for other future prospective studies.
\end{abstract}

Keywords: Pseudomonas aeruginosa, Cystic fibrosis, aPCR, Early detection

\section{Background}

Pseudomonas aeruginosa is the major pathogen involved in the decline of lung function in patients with cystic fibrosis (CF) [1-5]. Its presence in the lungs is associated with an increased mortality and morbidity of CF patients [6]. Early detection of this bacterium from respiratory tract is determinant because it ensures effective patient management $[5,7,8]$. Indeed, after intermittent colonization by different strains, once acquired, chronic $P$. aeruginosa colonization by mucoid and biofilm-growing isolates is difficult to eradicate $[2,4,9,10]$. Thus, the earlier the treatment

\footnotetext{
* Correspondence: hery@univ-brest.fr

'EA 3882-Laboratoire de Biodiversité et d'Ecologie Microbienne (LUBEM), SFR 148 SclnBioS, Faculté de Médecine, Université de Brest, Brest F-29200, France ${ }^{2}$ Département de Bactériologie-Virologie, Hygiène Hospitalière et Parasitologie-Mycologie, CHRU Brest, Brest F-29200, France

Full list of author information is available at the end of the article
}

toward $P$. aeruginosa onset, the higher the chance to efficiently control $P$. aeruginosa $[5,7,8]$.

However, accurate identification of this bacterium in CF sputum by conventional microbiology techniques is known to be limited. This can be explained by a large phenotypic diversity of $P$. aeruginosa isolates recovered from CF patients such as loss of pigment production or exopolysaccharide production. Moreover, Singh et al. demonstrated that $P$. aeruginosa can form biofilms in the airways of CF patients [11]. Biofilms contain bacterial cells that are in a wide range of physiological states. One of the mechanisms contributing to this physiological heterogeneity includes the adaptation to the local environmental conditions.

For instance, bacterial cells from the deep layers of biofilm depleted of oxygen [12] can grow in anaerobic

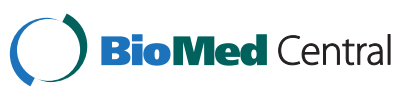


conditions. Therefore, the CF patients isolates obtained from biofilms, i.e. in anaerobic conditions, grow hardly in aerobic conditions on a conventional culture medium [13]. Another limitation of conventional culture is that $P$. aeruginosa can be easily misidentified with closely related Gram-negative bacilli in CF sputum [14-19].

The use of molecular techniques such as PCR could improve accurate identification of $P$. aeruginosa [14-19], and consequently, its early detection in CF sputum patients [20-24]. To date, there is no consensus for a universal protocol for the molecular detection of $P$. aeruginosa. Indeed, its genome is known to be highly polymorphic. Changes that can occur at the genetic level could compromise the reliability of molecular identification techniques. In particular in CF patients lungs, most of the recovered isolates are hypermutable $[2,4,25,26]$, and show a high genetic plasticity by acquisition or loss of genes $[27,28]$. Since mutations or gene deletions occur on PCR target sequences, they could decrease the sensitivity of the method [29]. Moreover, horizontal genetic transfer with other bacterial species present in the CF lung niche can impact upon the specificity of the PCR [14].

In a prospective multicenter study, we aimed to assess the role of PCR for the early detection of $P$. aeruginosa in CF patients; we evaluated two qPCRs in detection of $P$. aeruginosa: a simplex qPCR targeting oprL gene [30], and a multiplex qPCR, targeting $g y r \mathrm{~B}$ and ecf $\mathrm{X}$ genes [14]. The sensitivity and the specificity of both qPCRs were initially evaluated testing a large panel of $P$. aeruginosa isolates and closely related non- $P$. aeruginosa gram-negative bacilli isolates from $\mathrm{CF}$ patients. Then, the two different qPCRs ability in detection of $P$. aeruginosa were tested ex vivo, i.e in CF sputum samples. Finally, we were able to propose a promising reference protocol combining these two qPCRs for an optimal detection of $P$. aeruginosa in clinical setting.

\section{Methods}

\section{Bacterial collection}

Thirty-six $P$. aeruginosa isolates, including mucoid and non mucoid forms, were obtained from 31 sputum samples of CF patients and from 5 samples of non CF patients (blood, $n=1$; stool, $n=1$; urine, $n=1$; sputum, $n=1$; peritoneal fluid, $n=1$ ), attending three French University Hospitals, the CHRU of Brest $(n=3)$, the CHU of Nantes $(n=26)$, and the GHSR of Saint Pierre, La Réunion $(n=2)$. The reference strain $P$. aeruginosa CIP 76.110 was also included in the study.

Forty-one closely related non- $P$. aeruginosa gramnegative bacillus isolates were collected, including 26 obtained from sputum samples of CF patients, and 15 from clinical samples of non CF patients $(n=13)$ or environmental samples $(n=2)$. Sixteen species were represented: Achromobacter xylosoxidans $(n=9)$, P. putida $(n=5)$,
Stenotrophomonas maltophilia $(n=5)$, Burkholderia cepacia $(n=4), B$. multivorans $(n=3)$, B. gladioli $(n=2)$, Chryseobacterium indologenes $(n=2)$, Elizabethkingia meningoseptica $(n=2)$, P. stutzeri $(n=2)$, B. cenocepacia $(n=1)$, Flavimonas oryzihabitans $(n=1)$, Pandoraea pnomenusa $(n=1)$, P. fluorescens $(n=1)$, Ralstonia picketti $(n=1)$, Roseomonas spp. $(n=1)$, and Shewanella putrefaciens $(n=1)$.

Identification of bacterial isolates was previously conducted based on phenotypical and morphological criteria (colony morphology, pigmentation, lactose fermentation, oxidase activity checked with $1 \%$ tetramethyl $p$-phenylenediamine dihydrochloride, sensitivity to antibiotics). Atypical $P$. aeruginosa isolates, for which difficulties of identification were encountered, were further analyzed with biochemical tests [API 20NE system (bioMérieux, Marcy l'Etoile, France), ID 32GN (bioMérieux)], or with the gram-negative bacillus identification card on VITEK 2 Compact (bioMéreux). All non- $P$. aeruginosa gramnegative bacillus isolates were identified by $16 \mathrm{~S}$ rRNA gene sequencing as previously described [31].

All bacteria were stored at $-80^{\circ} \mathrm{C}$. Bacteria from frozen stocks were grown aerobically at $37^{\circ} \mathrm{C}$ for 24 to 48 hours on Muller-Hinton medium (bioMérieux).

\section{P. aeruginosa detection and quantification by sputum samples culture \\ CF patients and sample processing}

Fourty-six sputa were selected in line with our study objective. These CF sputum samples have been collected from 34 patients (median age: 11 years, range: 4-29, 53\% female) attending the CF center of Roscoff (France), between March 2008 and May 2012. At the time of CF patients inclusion, all of the patients were $P$. aeruginosa free for at least one year. More precisely, according to the Leeds definition [32], ten of them were never and 22 were free (Table 1). Each sputum sample was mixed with equal volume of dithiothreitol (Digesteur ${ }^{\circ}$ Eurobio, Courtaboeuf, France) and incubated at room temperature for $30 \mathrm{~min}$. For isolation of $P$. aeruginosa, liquefied sputa were immediately processed. For molecular detection of $P$. aeruginosa, two one-milliliter aliquots of every liquefied sputum were stored at $-80^{\circ} \mathrm{C}$.

\section{P. aeruginosa isolation}

Ten $\mu \mathrm{l}$ of liquefied sputum pure and diluted into $1 / 1000$, were inoculated and incubated onto several non selective and selective media for $P$. aeruginosa isolation, including Columbia blood agar supplemented with $5 \%$ defribinated horse blood (Oxoid, Dardilly, France), Columbia chocolate agar (Oxoid), and cetrimide agar (Oxoid). All media were incubated aerobically at $37^{\circ} \mathrm{C}$ for five days and monitored daily. All different morphotypes of bacterial colonies were identified phenotypically with 
Table 1 Quantification of Pseudomonas aeruginosa in CF sputum samples by culture and the oprL qPCR and detection by the gyrB/ecfX qPCR

\begin{tabular}{|c|c|c|c|c|c|}
\hline \multicolumn{2}{|l|}{ CF patient } & \multirow{2}{*}{$\begin{array}{l}\text { CF } \\
\text { sputum } \\
\text { sample }\end{array}$} & \multicolumn{2}{|c|}{ Quantification (CFU/mL) } & \multirow{2}{*}{$\begin{array}{l}\text { Multiplex qPCR } \\
\text { detection (gyrB/ecfX) }\end{array}$} \\
\hline Anonymisation number & P. aeruginosa category* & & By culture & By oprL qPCR** & \\
\hline \multirow[t]{3}{*}{003} & $\mathrm{~F}$ & 1 & $0.0 \mathrm{E}+00$ & $7.5 E+00$ & $-/-$ \\
\hline & & 2 & $0.0 \mathrm{E}+00$ & $1.4 \mathrm{E}+03$ & $+/-$ \\
\hline & & 3 & $2.0 \mathrm{E}+05$ & $2.7 \mathrm{E}+06$ & $+/+$ \\
\hline 004 & $\mathrm{~F}$ & 4 & $2.0 \mathrm{E}+03$ & $1.2 \mathrm{E}+05$ & $+/+$ \\
\hline 010 & $\mathrm{~F}$ & 5 & $1.0 \mathrm{E}+04$ & $9.9 E+06$ & $+/+$ \\
\hline \multirow[t]{4}{*}{012} & $\mathrm{~F}$ & 6 & $0.0 \mathrm{E}+00$ & $5.0 \mathrm{E}+01$ & $+/-$ \\
\hline & & 7 & $0.0 \mathrm{E}+00$ & $7.5 \mathrm{E}+01$ & $-/-$ \\
\hline & & 8 & $0.0 \mathrm{E}+00$ & $2.1 \mathrm{E}+02$ & $-/-$ \\
\hline & & 9 & $1.0 \mathrm{E}+07$ & $7.8 \mathrm{E}+06$ & $+/-$ \\
\hline 013 & $\mathrm{~F}$ & 10 & $1.0 \mathrm{E}+08$ & $4.0 \mathrm{E}+09$ & $+/+$ \\
\hline 014 & $\mathrm{~N}$ & 11 & $1.0 \mathrm{E}+06$ & $5.5 \mathrm{E}+06$ & $+/+$ \\
\hline 023 & $\mathrm{~N}$ & 12 & $4.0 \mathrm{E}+01$ & $2.5 \mathrm{E}+03$ & $+/-$ \\
\hline 024 & $\mathrm{~F}$ & 13 & $1.0 \mathrm{E}+03$ & $1.3 \mathrm{E}+05$ & $+/+$ \\
\hline \multirow[t]{2}{*}{025} & $\mathrm{~N}$ & 14 & $5.0 \mathrm{E}+04$ & $4.3 \mathrm{E}+07$ & $+/+$ \\
\hline & & 15 & $1.0 \mathrm{E}+05$ & $3.8 \mathrm{E}+03$ & $+/+$ \\
\hline 026 & $\mathrm{~N}$ & 16 & $2.0 \mathrm{E}+06$ & $6.7 \mathrm{E}+07$ & $+/+$ \\
\hline 028 & $\mathrm{~F}$ & 17 & $1.0 \mathrm{E}+04$ & $1.1 \mathrm{E}+05$ & $+/+$ \\
\hline 030 & $\mathrm{~F}$ & 18 & $1.0 \mathrm{E}+03$ & $1.3 \mathrm{E}+04$ & $+/+$ \\
\hline \multirow[t]{2}{*}{031} & $\mathrm{~N}$ & 19 & $1.0 \mathrm{E}+06$ & $1.2 \mathrm{E}+07$ & $+/+$ \\
\hline & & 20 & $2.0 \mathrm{E}+07$ & $1.0 \mathrm{E}+08$ & $+/+$ \\
\hline 034 & $\mathrm{~F}$ & 21 & $4.0 E+02$ & $6.8 \mathrm{E}+04$ & $+/+$ \\
\hline 035 & $\mathrm{~F}$ & 22 & $1.0 \mathrm{E}+04$ & $2.7 \mathrm{E}+04$ & $+/+$ \\
\hline 040 & $\mathrm{~F}$ & 23 & $1.0 \mathrm{E}+06$ & $1.4 \mathrm{E}+06$ & $+/+$ \\
\hline 041 & $\mathrm{~F}$ & 24 & $1.0 \mathrm{E}+02$ & $4.9 \mathrm{E}+01$ & $+/-$ \\
\hline 043 & $\mathrm{~N}$ & 25 & $6.0 \mathrm{E}+02$ & $5.6 \mathrm{E}+06$ & $+/+$ \\
\hline \multirow[t]{3}{*}{047} & $\mathrm{~N}$ & 26 & $0.0 \mathrm{E}+00$ & $1.1 \mathrm{E}+03$ & $+/+$ \\
\hline & & 27 & $0.0 \mathrm{E}+00$ & $5.3 \mathrm{E}+03$ & $+/+$ \\
\hline & & 28 & $1.0 \mathrm{E}+07$ & $1.1 \mathrm{E}+07$ & $+/+$ \\
\hline \multirow[t]{2}{*}{048} & $\mathrm{~F}$ & 29 & $0.0 \mathrm{E}+00$ & $8.1 \mathrm{E}+02$ & $+/+$ \\
\hline & & 30 & $4.0 \mathrm{E}+01$ & $2.5 \mathrm{E}+02$ & $+/+$ \\
\hline 053 & $\mathrm{~F}$ & 31 & $1.0 \mathrm{E}+02$ & $5.1 \mathrm{E}+03$ & $+/+$ \\
\hline \multirow[t]{2}{*}{054} & $\mathrm{~N}$ & 32 & $0.0 \mathrm{E}+00$ & $2.3 \mathrm{E}+01$ & $-/-$ \\
\hline & & 33 & $2.0 \mathrm{E}+05$ & $3.7 E+06$ & $+/+$ \\
\hline 057 & $\mathrm{~F}$ & 34 & $1.0 \mathrm{E}+06$ & $2.0 \mathrm{E}+01$ & $-/-$ \\
\hline 060 & $\mathrm{~F}$ & 35 & $4.0 \mathrm{E}+06$ & $1.5 E+08$ & $+/+$ \\
\hline 061 & $\mathrm{~F}$ & 36 & $1.0 \mathrm{E}+02$ & $6.1 \mathrm{E}+03$ & $+/+$ \\
\hline \multirow[t]{2}{*}{066} & $F$ & 37 & $4.0 E+03$ & $3.1 \mathrm{E}+04$ & $+/+$ \\
\hline & & 38 & $1.0 \mathrm{E}+04$ & $9.5 \mathrm{E}+06$ & $+/+$ \\
\hline 070 & $\mathrm{~N}$ & 39 & $1.0 \mathrm{E}+06$ & $9.0 \mathrm{E}+07$ & $+/+$ \\
\hline 072 & $F$ & 40 & $4.0 \mathrm{E}+04$ & $7.8 \mathrm{E}+07$ & $+/+$ \\
\hline 076 & F & 41 & $1.0 \mathrm{E}+03$ & $1.5 \mathrm{E}+04$ & $+/+$ \\
\hline 078 & $F$ & 42 & $1.0 \mathrm{E}+02$ & $2.0 \mathrm{E}+04$ & $+/+$ \\
\hline
\end{tabular}


Table 1 Quantification of Pseudomonas aeruginosa in CF sputum samples by culture and the oprL qPCR and detection by the gyrB/ecfX qPCR (Continued)

\begin{tabular}{|c|c|c|c|c|c|}
\hline 202 & $F$ & 43 & $1.0 \mathrm{E}+05$ & 1.7E + 05 & $+/-$ \\
\hline 205 & $\mathrm{~F}$ & 44 & $1.0 \mathrm{E}+03$ & $3.3 \mathrm{E}+06$ & $+/+$ \\
\hline 220 & F & 45 & $1.0 \mathrm{E}+06$ & $2.3 \mathrm{E}+08$ & $+/+$ \\
\hline 256 & N & 46 & $1.0 \mathrm{E}+03$ & $3.4 \mathrm{E}+04$ & $+/+$ \\
\hline mean & & & $3.3 \mathrm{E}+06$ & $1.2 \mathrm{E}+08$ & NA \\
\hline
\end{tabular}

*F: Free; N: Never (Lee et al., 2003).

**mean of quantification by oprL qPCR tested in duplicate.

NA: not applicable.

conventional screening methods (Gram coloration, oxidase test) followed by mass spectrometry identification (MicroFlex LT, Bruker Daltonics, Germany) [33,34]. Quantification was conducted based on the colony forming unit (CFU) counts and the dilution ratio of the plate.

\section{P. aeruginosa detection and quantification by quantitative PCR (qPCR) \\ DNA extraction}

For each isolate of the bacterial collection, $1 \mathrm{ml}$ of a 0.5 McFarland suspension was extracted. For each sputum sample, one of the two $1 \mathrm{ml}$-aliquots was treated by 5 min of sonication using a bath sonicator (Elamsonic S10, Singen, Germany). After a 10 min-centrifugation $(5000 \mathrm{~g})$, the pellet was suspended in $200 \mu \mathrm{l}$ of DNA free water. Ten $\mu \mathrm{l}$ of the IC2, an internal control provided in the DICO Extra r-gene ${ }^{\mathrm{mi}}$ kit (Argène, Verniolle, France), were added in each sample and, for each batch of extraction, in $200 \mu \mathrm{l}$ of DNA free water as a negative control. DNA was extracted using the QIAamp DNA Minikit ${ }^{\circ}$ (Qiagen, Courtaboeuf, France) according to the instructions of the manufacturer ("Tissue protocol") with elution volumes of $100 \mu \mathrm{l}$.

\section{oprL $q P C R$}

$o p r \mathrm{~L}$ qPCR was performed using primers $O P R L-\mathrm{F}$ and $O P R L-\mathrm{R}$ and hydrolysis probe oprL-MGB, previously described by Joly et al. [30] (Table 2). The reaction mix comprised $12.5 \mu \mathrm{l}$ of Qiagen Quantitect Probe Master Mix, $0.3 \mu \mathrm{M}$ of each primer, $0.2 \mu \mathrm{M}$ of hydrolysis probe and $4.5 \mu \mathrm{l}$ of DNA extract, and was made up to a final reaction volume of $25 \mu \mathrm{l}$ with water. A negative amplification control was used for each batch. For sputum samples, a standard curve provided a full concentration range of $P$. aeruginosa extending from $10^{2}$ to $10^{6} \mathrm{CFU} / \mathrm{mL}$. Each qPCR assay was repeated twice, and the mean value of the quantification was calculated for each duplicate (Table 1). Cycling was performed on an ABI Prism 7300 Real Time PCR System (Applied Biosystem, Foster city, Californy), with an initial hold at $95^{\circ} \mathrm{C}$ for $15 \mathrm{~min}$, followed by $50 \mathrm{cy}-$ cles at $95^{\circ} \mathrm{C}$ for $15 \mathrm{~s}$, and $60^{\circ} \mathrm{C}$ for $1 \mathrm{~min}$. The oprL-MGB probe was labelled with carboxyfluorescein (FAM).

\section{gyrB/ecfX qPCR}

The $P$. aeruginosa multiplex PCR was performed using primers ecf X-F, ecf $\mathrm{X}-\mathrm{R}$, gyr $\mathrm{B}-\mathrm{F}, \operatorname{gyr} \mathrm{B}-\mathrm{F}$, and hydrolysis probes ecfX-TM and gyr B-TM, previously described by Anuj in 2009 [14] (Table 2). The reaction mix comprised $12.5 \mu \mathrm{l}$ of Qiagen Quantitect Probe Master Mix, $0.4 \mu \mathrm{M}$ of each primer, $0.16 \mu \mathrm{M}$ of each hydrolysis probe, and $4.5 \mu \mathrm{l}$ of DNA extract and was made up to a final reaction volume of $25 \mu \mathrm{l}$ with free DNA water. All qPCR reaction plates contained negative amplification controls. For reaction plates containing sputum samples, a broadrange of $P$. aeruginosa concentrations from $10^{2}$ to

Table 2 Primers and probes used in this study for the detection and quantification of Pseudomonas aeruginosa

\begin{tabular}{llll}
\hline Name & Sequence $\left(\mathbf{5}^{\prime} \text { - } \mathbf{3}^{\prime}\right)^{*}$ & DNA target & Reference \\
\hline OPRL-F & AACAGCGGTGCCGTGAC & oprL & [30] \\
OPRL-R & GTCGGAGCTGTCGTACTCGAA & oprL & [30] \\
oprL-MGB & fam -TGAGCGACGAGCC-bhq & oprL & [30] \\
gyrB-F & CCTGACCATCCGTCGCCACAAC & gyrB & gyrB \\
gyrB-F & CGCAGCAGGATGCCGACGCC & gyrB & {$[19,36]$} \\
gyrB-TM & fam-CCGTGGTGGTAGACCTGTTCCCAGACC-bhq & ecfX & {$[19,36]$} \\
ecfX-F & CGCATGCCTATCAGGCGTT & ecfX & {$[14]$} \\
ecfX-R & GAACTGCCCAGGTGCTTGC & ecfX & {$[14]$} \\
ecfX-TM & yak-ATGGCGAGTGCTGCGCTTCCT-bhq & {$[14]$} \\
\hline
\end{tabular}

*yak = Yakima Yellow; fam = carboxyfluorescein; bhq = block hole quencher. 
$10^{6} \mathrm{CFU} / \mathrm{mL}$ was tested. Cycling was performed on an ABI Prism 7300 Real Time PCR System (Applied Biosystem), with an initial hold at $95^{\circ} \mathrm{C}$ for $15 \mathrm{~min}$, followed by 50 cycles at $95^{\circ} \mathrm{C}$ for $15 \mathrm{~s}$, and $60^{\circ} \mathrm{C}$ for $1 \mathrm{~min}$. The gyrB-TM probe was labelled with carboxyfluorescein (FAM), whereas the ecfX-TM probe was labeled with a Yakima Yellow fluorophore, enabling the reaction to be distinguished using the ABI 7300 FAM and JOE detection channels, respectively. Results were analyzed by the 7300 System SDS logiciel (Applied biosystem). The gyrB/ecf X qPCR was considered positive when at least one of the two target genes was detected.

\section{DICO extra r-gene amplification}

Ten microliter of extracted sputum samples were distributed in $15 \mu \mathrm{l}$ of the DICO Extra r-gene premix (DP2, Argène) with $0.1 \mu \mathrm{l}$ of the HotStarTaq ${ }^{\text {Tix }}$ (Qiagen). The amplification program recommended by the manufacturer was applied on the automate ABI Prism 7300 Real Time PCR System (Applied Biosystem). The validation of both DNA isolation and amplification procedures, as well as the samples result interpretation, were conducted according to the instructions by Argene.

\section{Determination of the lower detection threshold}

To determine the lower detection threshold, six dilution ranges were realized with six different $P$. aeruginosa isolates. One range was prepared with the reference strain (CIP 76.110), two with a mucoid and a non-mucoid isolates from a sputum sample of a CF patient, and three with three isolates from three non-CF patients (urine, $n=1$; blood, $n=1$; stool, $n=1$ ). Ten fold iterative dilutions from 0.5 McFarland calibrated $P$. aeruginosa suspensions provided a full concentration range extending from $10^{0}$ to $10^{8} \mathrm{CFU} / \mathrm{mL}$. The nine dilutions of the range were tested 30 times. To determine the exact inoculum of each dilution range, a plate counting was carried out on a Mueller-Hinton medium (bioMérieux) incubated from 24 to 48 hours at $30^{\circ} \mathrm{C}$. A mean of the results was calculated taking into account the sum of all assays.

\section{Ethics}

The Comité de Protection des Personnes Ouest VI approved the protocol. All of the patients and their relatives gave written informed consent. The collection of archival specimens was registered with the French Ministry of Research and the Agence Régionale de l'Hospitalisation, No. DC-2008-214.

\section{Results}

\section{In vitro characteristics of the oprL and gyrB/ecfX qPCR} Sensitivity

The two qPCRs showed 100\% sensitivity. At the concentration of $10^{6} \mathrm{CFU} / \mathrm{mL}$, all the $37 \mathrm{P}$. aeruginosa isolates were detected by the two qPCRs. The cycle treshold (Cq) mean was 24.8 and 24/28.2 respectively for the oprL qPCR and the gyrB/ecfX qPCR.

\section{Specificity}

The specificity of the oprL qPCR was evaluated at $73 \%$. At the concentration of $10^{6} \mathrm{CFU} / \mathrm{mL}$, eleven isolates out of the 41 non- $P$. aeruginosa gram-negative bacillus isolates, corresponding to six different species, were amplified by the oprL qPCR. The six species responsible for cross-reactions were A. xylosoxidans, B. cenocepacia, $B$. multivorans, E. meningoseptica, Roseomonas spp., and $S$. maltophilia (Table 3). By considering the gyr B/ecf $\mathrm{X}$ qPCR positive when at least one of the two targeted genes was amplified, the specificity was calculated at $90 \%$. Four out of the 41 isolates corresponding to four different species induced false positive reactions in at least one of their assays (Table 3): C. indologenes, F. oryzihabitans, $P$. putida and $P$. stutzeri. No species cross-reacted with both qPCRs. In this manner, combining oprL and $g y r \mathrm{~B} / e c f \mathrm{X}$ amplifications allowed achieving $100 \%$ specificity.

\section{Lower detection threshold}

The lower detection threshold of the oprL qPCR was evaluated at $10 \mathrm{CFU} / \mathrm{mL}$. Given a positive multiplex PCR when at least one of the two probes was detected, the detection threshold of the gyrB/ecf X qPCR was evaluated at $730 \mathrm{CFU} / \mathrm{mL}$.

Table 3 Bacterial species responsible for false positive amplifications with the oprL and gyrB/ecfX qPCRs

\begin{tabular}{|c|c|c|c|}
\hline Species & $\begin{array}{l}\text { Number of isolates } \\
\text { PCR+ / number of } \\
\text { isolates tested }\end{array}$ & $\begin{array}{l}\text { oprL qPCR } \\
\text { results }\end{array}$ & $\begin{array}{l}\text { gyrB/ecfX } \\
\text { qPCR results }\end{array}$ \\
\hline $\begin{array}{l}\text { Achromobacter } \\
\text { xylosoxidans }\end{array}$ & $6 / 9$ & + & $-/-$ \\
\hline $\begin{array}{l}\text { Burkholderia } \\
\text { cenocepacia }\end{array}$ & $1 / 1$ & + & $-/-$ \\
\hline $\begin{array}{l}\text { Burkholderia } \\
\text { multivorans }\end{array}$ & $1 / 3$ & + & $-/-$ \\
\hline $\begin{array}{l}\text { Chryseobacterium } \\
\text { indologenes }\end{array}$ & $1 / 2$ & - & $+/+$ \\
\hline $\begin{array}{l}\text { Elizabethkingia } \\
\text { meningoseptica }\end{array}$ & $1 / 2$ & + & $-1-$ \\
\hline $\begin{array}{l}\text { Flavimonas } \\
\text { oryzihabitans }\end{array}$ & $1 / 1$ & - & $+/+$ \\
\hline $\begin{array}{l}\text { Pseudomonas } \\
\text { putida }\end{array}$ & $1 / 5$ & - & $-1+$ \\
\hline $\begin{array}{l}\text { Pseudomonas } \\
\text { stutzeri }\end{array}$ & $1 / 2$ & - & $-1+$ \\
\hline Roseomonas spp. & $1 / 1$ & + & $-/-$ \\
\hline $\begin{array}{l}\text { Stenotrophomonas } \\
\text { maltophilia }\end{array}$ & $1 / 5$ & + & $-/-$ \\
\hline
\end{tabular}




\section{Ex vivo validation of the detection and quantification of $P$. aeruginosa in CF sputa by the two qPCRs}

The opr $\mathrm{L}$ qPCR detected $P$. aeruginosa in all the $46 \mathrm{CF}$ sputum samples. The multiplex PCR failed to detect the bacterium in five samples. The mean quantification of $P$. aeruginosa of these samples was evaluated at 67.1 CFU/mL, i.e. under the lower detection threshold of the $g y r \mathrm{~B} / \operatorname{ecf} \mathrm{X}$ qPCR. For six of the 46 samples, only one probe $(g y r \mathrm{~B})$ was detected positive. Comparison of the results of $P$. aeruginosa quantification in CF sputum samples by culture and oprL qPCR is reported in Table 1. For 37 out of the 46 sputum samples tested, the quantification found by PCR is at least one $\log$ above the one found by culture. In average, for the 46 tested sputum samples, the molecular quantification of $P$. aeruginosa was two logs higher than the conventional culture quantification $(1.2 \mathrm{E}+08 \mathrm{CFU} / \mathrm{mL}$ versus $3.3 \mathrm{E}+06 \mathrm{CFU} / \mathrm{mL})$.

\section{Consistency between in vitro and ex vivo experiments}

The theoretical threshold calculated from in vitro experiments was totally consistent with the observed threshold from ex vivo experiments. Indeed, oprL qPCR assays performed ex vivo identified one hundred times more bacterial cells than culture-based methods did. Thus, the theoretical lower detection threshold of oprL qPCR of $10 \mathrm{CFU} / \mathrm{mL}$ calculated from in vitro cultures is equivalent to a threshold of $1 \mathrm{E}+03 \mathrm{CFU} / \mathrm{mL}$ if applied ex vivo. This was verified on 9 culture-/PCR + samples for which the quantification by oprL qPCR retrieved a mean of quantification of $997.3 \mathrm{CFU} / \mathrm{mL}$.

The theoretical lower detection of the multiplex qPCR was found at $7.3 \mathrm{E}+02 \mathrm{CFU} / \mathrm{mL}$ in vitro. Ex vivo, the amplification conducted on the sputum samples showed a positive signal for at least one target ( $g y r \mathrm{~B}$ or ecf $\mathrm{X}$ ) for all of the $P$. aeruginosa-positive sputa with quantification above $7.3 \mathrm{E}+02 \mathrm{CFU} / \mathrm{mL} \quad(\mathrm{n}=38)$. On the contrary, below $7.3 \mathrm{E}+02 \mathrm{CFU} / \mathrm{mL}$, the majority (5 of 8 samples) of the sputa that were $P$. aeruginosa-positive by opr $\mathrm{L}$ PCR, were $P$. aeruginosa-negative by multiplex PCR.

To conclude, the theoretical thresholds of both qPCRs were verified on the sputum samples.

\section{Discussion and conclusion}

Several studies have suggested that qPCR is superior to culture for detecting early colonization of $P$. aeruginosa in CF sputum [20,22-24]. Today, the main goal is to have an optimal protocol as the gold standard for the molecular detection of $P$. aeruginosa. Therefore, we performed in vitro and ex vivo evaluation of two qPCRs, one targeting the oprL gene and the other targeting simultaneously gyrB and ecf $\mathrm{X}$ genes [14,30]. Numerous DNA targets have been described for the amplification of $P$. aeruginosa $[15,17,19,34-36]$, of these three housekeeping genes, opr $\mathrm{L}, \operatorname{gyr} \mathrm{B}$ and $\operatorname{ecf} \mathrm{X}$ have been reported to be reliable targets in the detection of $P$. aeruginosa [14,19,30,35].

The first criterion for an optimal technique in early detection of $P$. aeruginosa in CF sputum is related to the choice of the PCR format and its optimization. Today, the DNA molecules counting of a particular sequence in a complex sample can be achieved with exceptional accuracy and sensitivity sufficient to detect a single molecule [36]. As underlined by Deschagt et al. [35], the choice of PCR format may influence the performance of the molecular detection. We chose a probe-based assay, which is known to be more sensitive and specific than the SYBR Green-based qPCR [35].

The second criterion is a good sensitivity to prevent false negative results. Despite wide genetic variability of $P$. aeruginosa isolates recovered from CF patients [2,4,25-28], results of previous studies aiming at detecting $P$. aeruginosa by PCR have been encouraging. In our study, both evaluated qPCRs showed an excellent sensitivity covering all the tested panel of $P$. aeruginosa isolates. Focusing on the lower detection threshold, the difference was significant between the two qPCR assays with a detection threshold of $10 \mathrm{CFU} / \mathrm{mL}$ for the oprL qPCR versus $730 \mathrm{CFU} / \mathrm{mL}$ for the multiplex PCR. The sensitivity of the in vitro oprL qPCR in our study was higher than that recommended by the French guidelines, i.e. a detection threshold of $10^{2} \mathrm{CFU} / \mathrm{mL}$ for CF sputum sample [37].

The third criterion needed for early $P$. aeruginosa detection technique, in particular, for molecular one, is to have a high specificity to prevent false positive amplification. When looking at a large panel of genes described in the literature e.g. oprI, oprL, $r r l$, ecf $\mathrm{X}, g y r \mathrm{~B}$, or $r r s$, specificity varied from $74 \%$ to $100 \%$ [14,17,34-36,38]. In our study, specificity of the oprL qPCR was evaluated at $73 \%$ versus $90 \%$ for the multiplex PCR. Four previous studies have tested the specificity of the oprL primer pairs and found different values ranging from $87 \%$ to $100 \%$ $[22,34,35,38]$. Again, previous studies looking at $g y r B$ and ecfX genes found a better specificity $(100 \%)$ than in our study [14,35]. Different reasons could explain these discrepancies. Firstly, our specificity could have been influenced by a larger panel of closely related non $P$. aeruginosa gram-negative bacilli (41 isolates including 16 different species). Secondly, all the bacterial isolates (except one reference strain) were recovered from clinical samples (CF or non $\mathrm{CF}$ ) or from environmental samples. These isolates, which were recovered from $\mathrm{CF}$ could have undergone genetic exchange with other species in the natural CF microenvironment, especially $P$. aeruginosa, influencing the specificity of the molecular method [38]. Thus, specificity in previous studies could have been overestimated $[14,34,35,38]$. As highlighted by 
Anuj et al. $[14,35]$, the higher specificity of our results for the multiplex PCR may be explained by the fact that we amplified at least 2 DNA targets. The use of two probes simultaneously seems to improve the specificity, providing at the same time the detection and the confirmation of the presence of $P$. aeruginosa $[14,19]$. Interestingly, our bacterial species that cross-reacted with the oprL qPCR did not do so when oprL qPCR was combined with the multiplex PCR thus allowing 100\% specificity.

These results were successfully validated by the sputum samples of CF patients from the never or free categories according to the definition of Leeds [32]. The ex vivo experiments put forward a significant difference between the culture-based quantification and the qPCRbased quantification. In average, the qPCR detected 100 times more CFU of $P$. aeruginosa than the culture did.

This could be explained by different hypotheses. First, the difference in utilized sputum volumes contributes to this discrepancy. Indeed, only $10 \mu \mathrm{l}$ were cultured whereas $1 \mathrm{ml}$ was extracted for the qPCR. The lowest concentration that theoretically can be detected by qPCR equals the presence of one genome (i.e. equivalent to one CFU) per qPCR reaction mixture. Using $1 \mathrm{ml}$ of 10 -fold concentrated sputum by centrifugation and extraction (elution volume of $100 \mu \mathrm{l}$ ) and $4.5 \mu \mathrm{l}$ for the PCR reaction (final volume of $25 \mu \mathrm{l}$ ), the detection limit of our molecular diagnosis is $\approx 22 \mathrm{CFU} / \mathrm{mL}$. In comparison, the lowest concentration that theoretically can be detected by culture is $100 \mathrm{CFU} / \mathrm{mL}$.

Second, given the phenotypic diversity of $P$. aeruginosa isolates and the large diversity of species found in pulmonary microbiota, the detection of $P$. aeruginosa by culture in CF sputum is a hard task [14-19]. Moreover, culture in aerobic conditions can fail in the detection of some isolates adapted to anaerobic conditions of the $\mathrm{CF}$ lung niche [13], or of non-cultivable isolates present in the bacterial biofilm [39].

Another explanation could be that qPCR detects $P$. aeruginosa DNA, i.e. not only live bacteria but also dead cells [40]. As CF patients are chronically treated with antibiotics, one can suppose that dead bacteria are significantly present in the pulmonary tract. In a study lead by Deschaght et al. in 2009, no difference in sensitivity between culture and oprL qPCR was found [41]. Their study was conducted on eight artificial $P$. aeruginosa-positive sputum pre-liquefied samples thus skipping the sample homogenization step, one of the cornerstones in amplification-based technique. Our ex vivo application of the two qPCR assays with real samples took into account the sample homogenization. It also put forward the importance of having a controlled amplification assay in particular to avoid false negatives due to inhibitors or a bad extraction. Indeed, the DNA-extraction method has been shown to be a critical step in the PCR performances [41]. In our study, we chose the DICO Extra r-gene kit, a totally

\section{oprL PCR}

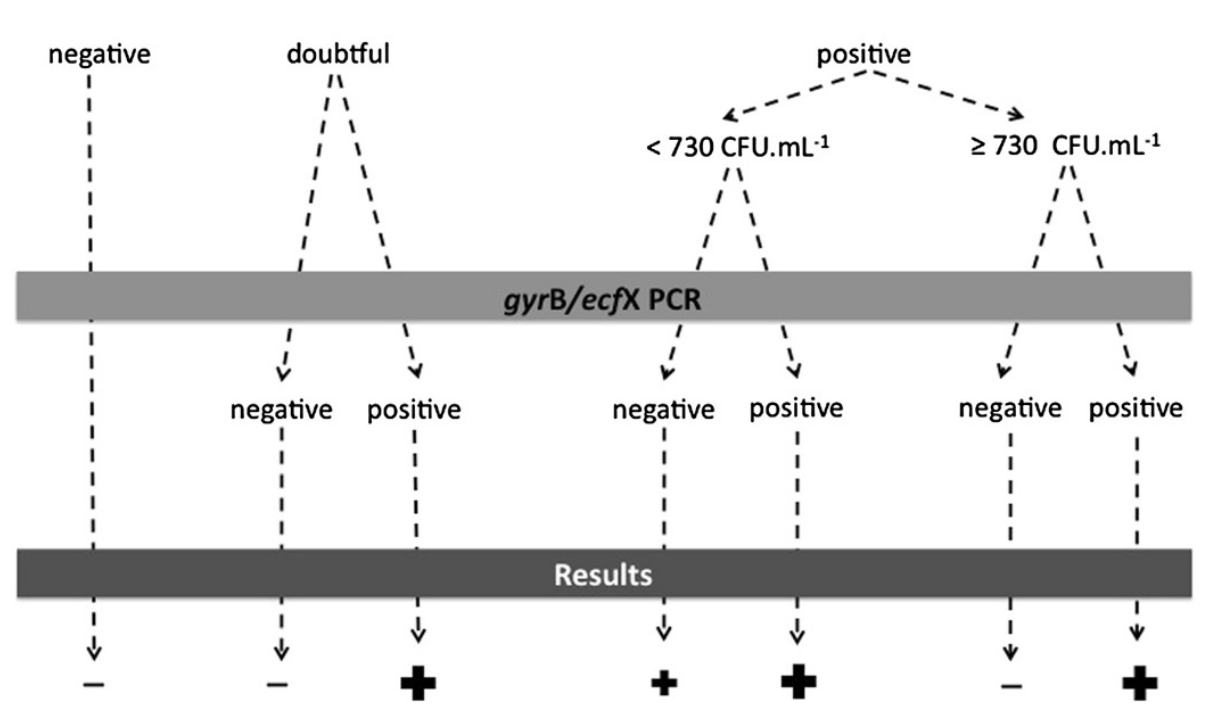

Figure 1 Proposal of a molecular protocol integrating two qPCR formats (targeting oprL and gyrB/ecfX genes) for an early detection of Pseudomonas aeruginosa in sputum samples of patients with cystic fibrosis. The oprL $\mathrm{qPCR}$ is applied in screening because of its good sensitivity. In case of a doubtful or a positive result, the gyrB/ecfX qPCR is applied in a second time. Interpretation of the gyrB/ecfX qPCR takes into account the quantification found with oprL qPCR. Below the detection threshold of $730 \mathrm{CFU} / \mathrm{mL}$, the oprL qPCR prevails over the gyrB/ecfX qPCR. Conversely, beyond this threshold, the gyrB/ecfX qPCR prevails over the oprL qPCR. 
artificial DNA, as internal control, which prevents from contamination during procedure handling, and allows to test extraction and amplification at the same time.

Altogether, our study showed that the oprL qPCR offers a good sensitivity whereas the multiplex PCR offers a good specificity. Based on these data, we decided to combine these two qPCR assays and proposed a molecular protocol for an optimal detection of $P$. aeruginosa by qPCR in CF sputum as follows (Figure 1). The oprL qPCR can be applied in screening because of its good sensitivity. In case of a doubtful or a positive result, we can proceed to the multiplex PCR. Interpretation of the multiplex PCR takes into account the quantification found with oprL PCR. Below the detection threshold of $730 \mathrm{CFU} / \mathrm{mL}$, the oprL qPCR prevails over the multiplex PCR. Conversely, beyond this threshold, the multiplex PCR prevails over the oprL qPCR. Overall, this combined molecular protocol offers a sensitivity of $100 \%$ with a threshold of $10 \mathrm{CFU} / \mathrm{mL}$ and a specificity of $100 \%$.

This qPCR-based combined protocol can be adapted for instance in a subgroup of non-sputum producing patients and used for other future prospective studies. Indeed, the initial colonization of $P$. aeruginosa often occurs in CF patients who do not produce sputum (e.g. mainly children). This qPCR format should therefore be tested on the sample secretions routinely obtained from, e.g. deep throat swabs or endolaryngeal suction.

\section{Competing interests}

The authors declare that they have no competing interests.

\section{Authors' contributions}

GHA, FLG, and RLB conceived the study and designed the experiments. FLG, GHA and RLB wrote the manuscript. FLG, SR, JH, SG and GHA performed the experiments. SBG, SV, CP and GR helped with the manuscript discussion. All authors have read and approved the final manuscript.

\section{Acknowledgments}

This study was supported by a grant from the French Cystic Fibrosis Association "Vaincre la Mucoviscidose" (contract No. RCO 1773). This study was presented in part at the $4^{\text {th }}$ Congress of European Microbiologists FEMS, 26-30 June 2011, Geneva, Switzerland. The authors thank Jocelyne Caillon, and Alain Michault for providing some of the isolates used in this study. We are indebted to Zarrin Alavi for critical reading of the manuscript.

\section{Author details}

'EA 3882-Laboratoire de Biodiversité et d'Ecologie Microbienne (LUBEM), SFR 148 ScInBioS, Faculté de Médecine, Université de Brest, Brest F-29200, France. ${ }^{2}$ Département de Bactériologie-Virologie, Hygiène Hospitalière et Parasitologie-Mycologie, CHRU Brest, Brest F-29200, France. ${ }^{3}$ Département de Médecine Interne et Pneumologie, CHRU Brest, Brest F-29200, France. ${ }^{4}$ INSERM-CIC 0502, CHRU Brest, Brest F-29200, France. ${ }^{5}$ Centre de Perharidy, CRCM, Roscoff F-29680, France.

Received: 16 January 2013 Accepted: 13 June 2013

Published: 21 June 2013

\section{References}

1. Ballmann M, Rabsch P, von der Hardt H: Long-term follow up of changes in FEV1 and treatment intensity during Pseudomonas aeruginosa colonisation in patients with cystic fibrosis. Thorax 1998, 53(9):732-737.

2. Ciofu O, Riis B, Pressler T, Poulsen HE, Hoiby N: Occurrence of hypermutable Pseudomonas aeruginosa in cystic fibrosis patients is associated with the oxidative stress caused by chronic lung inflammation. Antimicrob Agents Chemother 2005, 49(6):2276-2282.

3. Nixon GM, Armstrong DS, Carzino R, Carlin JB, Olinsky A, Robertson CF, Grimwood K: Clinical outcome after early Pseudomonas aeruginosa infection in cystic fibrosis. J Pediatr 2001, 138(5):699-704.

4. Oliver A, Mena A: Bacterial hypermutation in cystic fibrosis, not only for antibiotic resistance. Clin Microbiol Infect 2010, 16(7):798-808.

5. Stuart B: Early eradication of pseudomonas aeruginosa in patients with cystic fibrosis. Paediatr Respi Rev 2010, 11(3):177-184.

6. Gibson RL, Burns JL, Ramsey BW: Pathophysiology and management of pulmonary infections in cystic fibrosis. Am J Respir Crit Care Med 2003, 168(8):918-951.

7. Hoiby N, Frederiksen B, Pressler T: Eradication of early Pseudomonas aeruginosa infection. J Cyst Fibros 2005, 4(Suppl 2):49-54.

8. Valerius NH, Koch C, Hoiby N: Prevention of chronic Pseudomonas aeruginosa colonisation in cystic fibrosis by early treatment. Lancet 1991, 338(8769):725-726.

9. Oliver A, Canton R, Campo P, Baquero F, Blazquez J: High frequency of hypermutable Pseudomonas aeruginosa in cystic fibrosis lung infection. Science 2000, 288(5469):1251-1254.

10. Pierre M, Le Berre R, Tiesset H, Faure K, Guery B, Desseyn JL, Galabert C, Beghin L, Beermann C, Gottrand F, et al: Kinetics of Pseudomonas aeruginosa virulence gene expression during chronic lung infection in the murine model. Med Mal Infect 2008, 38(6):318-323.

11. Singh PK, Schaefer AL, Parsek MR, Moninger TO, Welsh MJ, Greenberg EP: Quorum-sensing signals indicate that cystic fibrosis lungs are infected with bacterial biofilms. Nature 2000, 407(6805):762-764.

12. Stewart PS, Franklin MJ: Physiological heterogeneity in biofilms. Nat Rev Microbiol 2008, 6(3):199-210.

13. O'May CY, Reid DW, Kirov SM: Anaerobic culture conditions favor biofilmlike phenotypes in Pseudomonas aeruginosa isolates from patients with cystic fibrosis. FEMS Immunol Med Microbiol 2006, 48(3):373-380.

14. Anuj SN, Whiley DM, Kidd TJ, Bell SC, Wainwright CE, Nissen MD, Sloots TP: Identification of Pseudomonas aeruginosa by a duplex real-time polymerase chain reaction assay targeting the ecfX and the gyr $B$ genes. Diagn Microbiol Infect Dis 2009, 63(2):127-131.

15. Kidd TJ, Ramsay KA, Hu H, Bye PT, Elkins MR, Grimwood K, Harbour C, Marks GB, Nissen MD, Robinson PJ, et al: Low rates of Pseudomonas aeruginosa misidentification in isolates from cystic fibrosis patients. J Clin Microbiol 2009, 47(5):1503-1509.

16. Wellinghausen N, Kothe J, Wirths B, Sigge A, Poppert S: Superiority of molecular techniques for identification of gram-negative, oxidase-positive rods, including morphologically nontypical Pseudomonas aeruginosa, from patients with cystic fibrosis. J Clin Microbiol 2005, 43(8):4070-4075.

17. Spilker T, Coenye T, Vandamme P, LiPuma JJ: PCR-based assay for differentiation of Pseudomonas aeruginosa from other Pseudomonas species recovered from cystic fibrosis patients. J Clin Microbiol 2004, 42(5):2074-2079.

18. Ferroni A, Sermet-Gaudelus I, Abachin E, Quesnes G, Lenoir G, Berche P, Gaillard JL: Phenotypic and genotypic characteristics of non fermenting atypical strains recovered from cystic fibrosis patients. Pathol Biol (Paris) 2003, 51(7):405-411.

19. Qin X, Emerson J, Stapp J, Stapp L, Abe P, Burns JL: Use of real-time PCR with multiple targets to identify Pseudomonas aeruginosa and other nonfermenting gram-negative bacilli from patients with cystic fibrosis. J Clin Microbiol 2003, 41(9):4312-4317.

20. Xu J, Moore JE, Murphy PG, Millar BC, Elborn JS: Early detection of Pseudomonas aeruginosa-comparison of conventional versus molecular (PCR) detection directly from adult patients with cystic fibrosis (CF). Ann Clin Microbiol Antimicrob 2004, 3:21.

21. Deschaght P, Schelstraete P, Lopes dos Santos Santiago G, Van Simaey L, Haerynck F, Van Daele S, De Wachter E, Malfroot A, Lebecque P, Knoop C, et al: Comparison of culture and qPCR for the detection of Pseudomonas aeruginosa in not chronically infected cystic fibrosis patients. BMC Microbiol 2010, 10:245.

22. Billard-Pomares T, Herwegh S, Wizla-Derambure N, Turck D, Courcol R, Husson MO: Application of quantitative PCR to the diagnosis and monitoring of Pseudomonas aeruginosa colonization in 5-18-year-old cystic fibrosis patients. J Med Microbiol 2011, 60(Pt 2):157-161.

23. Logan C, Habington A, Lennon G, Cronin F, O'Sullivan N: Evaluation of the efficacy of real-time polymerase chain reaction for the routine early 
detection of Pseudomonas aeruginosa in cystic fibrosis sputum and throat swab specimens. Diagn Microbiol Infect Dis 2010, 68(4):358-365.

24. McCulloch E, Lucas C, Ramage G, Williams C: Improved early diagnosis of Pseudomonas aeruginosa by real-time PCR to prevent chronic colonisation in a paediatric cystic fibrosis population. J Cyst Fibros 2011, 10(1):21-24.

25. Hoboth C, Hoffmann R, Eichner A, Henke C, Schmoldt S, Imhof A, Heesemann J, Hogardt M: Dynamics of adaptive microevolution of hypermutable Pseudomonas aeruginosa during chronic pulmonary infection in patients with cystic fibrosis. J Infect Dis 2009, 200(1):118-130.

26. Mena A, Smith EE, Burns JL, Speert DP, Moskowitz SM, Perez JL, Oliver A: Genetic adaptation of Pseudomonas aeruginosa to the airways of cystic fibrosis patients is catalyzed by hypermutation. J Bacteriol 2008, 190(24):7910-7917.

27. Finnan S, Morrissey JP, O'Gara F, Boyd EF: Genome diversity of Pseudomonas aeruginosa isolates from cystic fibrosis patients and the hospital environment. J Clin Microbiol 2004, 42(12):5783-5792.

28. Mathee K, Narasimhan G, Valdes C, Qiu X, Matewish JM, Koehrsen M, Rokas A, Yandava CN, Engels R, Zeng E, et al: Dynamics of Pseudomonas aeruginosa genome evolution. Proc Natl Acad Sci USA 2008, 105(8):3100-3105.

29. Whiley DM, Lambert SB, Bialasiewicz S, Goire N, Nissen MD, Sloots TP: Falsenegative results in nucleic acid amplification tests-do we need to routinely use two genetic targets in all assays to overcome problems caused by sequence variation? Crit Rev Microbiol 2008, 34(2):71-76.

30. Joly B, Pierre M, Auvin S, Colin F, Gottrand F, Guery B, Husson MO: Relative expression of Pseudomonas aeruginosa virulence genes analyzed by a real time RT-PCR method during lung infection in rats. FEMS Microbiol Lett 2005, 243(1):271-278.

31. Moissenet $\mathrm{D}$, Bingen $\mathrm{E}$, Arlet $\mathrm{G}, \mathrm{Vu}$-Thien $\mathrm{H}$ : Use of $16 \mathrm{~S}$ rRNA gene sequencing for identification of "Pseudomonas-like" isolates from sputum of patients with cystic fibrosis. Pathol Biol (Paris) 2005, 53(8-9):500-502.

32. Lee TW, Brownlee KG, Conway SP, Denton M, Littlewood JM: Evaluation of a new definition for chronic Pseudomonas aeruginosa infection in cystic fibrosis patients. J Cyst Fibros 2003, 2(1):29-34

33. Degand N, Carbonnelle E, Dauphin B, Beretti JL, Le Bourgeois M, SermetGaudelus I, Segonds C, Berche P, Nassif X, Ferroni A: Matrix-assisted laser desorption ionization-time of flight mass spectrometry for identification of nonfermenting gram-negative bacilli isolated from cystic fibrosis patients. J Clin Microbiol 2008, 46(10):3361-3367.

34. Desai AP, Stanley T, Atuan M, McKey J, Lipuma JJ, Rogers B, Jerris R: Use of matrix assisted laser desorption ionisation-time of flight mass spectrometry in a paediatric clinical laboratory for identification of bacteria commonly isolated from cystic fibrosis patients. J Clin Pathol 2012, 65(9):835-838.

35. Deschaght P, Van Daele S, De Baets F, Vaneechoutte M: PCR and the detection of Pseudomonas aeruginosa in respiratory samples of CF patients. A literature review. J Cyst Fibros 2011, 10(5):293-297.

36. Kubista M, Andrade JM, Bengtsson M, Forootan A, Jonak J, Lind K, Sindelka R, Sjoback R, Sjogreen B, Strombom L, et al: The real-time polymerase chain reaction. Mol Aspects Med 2006, 27(2-3):95-125.

37. Anonyme: Recommandations pour l'analyse bactériologique des prélèvements d'expectoration chez les patients atteints de mucoviscidose. In REMIC - Référentiel en microbiologie médicale. 2nd edition. Edited by Société Française de Microbiologie. Paris; 2010:99-104.

38. Davison J: Genetic exchange between bacteria in the environment. Plasmid 1999, 42(2):73-91.

39. Aparna MS, Yadav S: Biofilms: microbes and disease. Braz J Infect Dis 2008, 12(6):526-530.

40. Masters Cl, Shallcross JA, Mackey BM: Effect of stress treatments on the detection of Listeria monocytogenes and enterotoxigenic Escherichia coll by the polymerase chain reaction. J Appl Bacteriol 1994, 77(1):73-79.

41. Deschaght P, De Baere T, Van Simaey L, Van Daele S, De Baets F, De Vos D, Pirnay JP, Vaneechoutte M: Comparison of the sensitivity of culture, PCR and quantitative real-time PCR for the detection of Pseudomonas aeruginosa in sputum of cystic fibrosis patients. BMC Microbiol 2009, 9:244.

\section{doi:10.1186/1471-2180-13-143}

Cite this article as: Le Gall et al:: Proposal of a quantitative PCR-based protocol for an optimal Pseudomonas aeruginosa detection in patients with cystic fibrosis. BMC Microbiology 2013 13:143. 